\title{
Prevalence and predictors of over-the-counter medication use among adolescents in the United Arab Emirates
}

Caroline Barakat-Haddad ${ }^{7}$ and Ayesha Siddiqua ${ }^{2}$

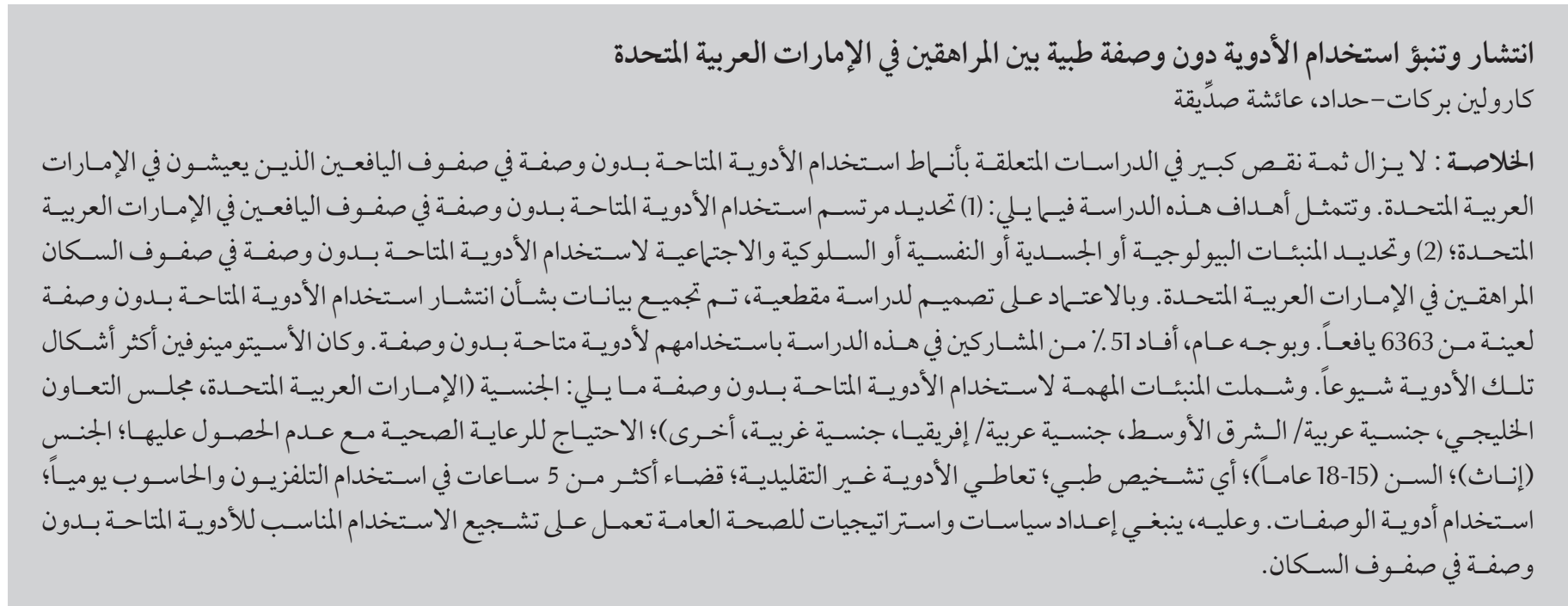

ABSTRACT The patterns of over-the-counter medication (OTC) usage among adolescents living in the United Arab Emirates (UAE) remains largely understudied. The objectives of this study are: (1) to determine the profile of OTC use among UAE adolescents; and (2) to determine the biological or physical, psychological or behavioural, and social predictors of OTC use among the UAE adolescent population. Using a cross-sectional study design, data were collected on the prevalence of OTC use for a sample of 6363 adolescents. Overall, 51\% of participants in this study reported OTC use. The most common form of OTC used was acetaminophen. Significant predictors of OTC use were: nationality (UAE, GCC, Arab / Middle East, Arab / Africa, Western, other); needed health care but did not receive it; sex (female); age (15-18 years); any medical diagnosis; unconventional drug use; spending more than 5 hours using TV and computer daily; and using prescription medicines. Thus, there is a need to develop public health policies and strategies that promote appropriate use of OTC in the population.

\section{Prévalence et facteurs prédictifs de l'automédication chez les adolescents aux Émirats arabes unis}

RÉSUMÉ Les formes de l'automédication chez les adolescents des Émirats arabes unis (EAU) demeurent largement sousdocumentées. La présente étude a pour objectifs de $: 1$ ) déterminer le profil de l'automédication chez les adolescents des Émirats arabes unis; et 2) de déterminer les facteurs prédictifs biologiques ou physiques, psychologiques ou comportementaux, et sociaux de cette pratique parmi la population d'adolescents des Émirats arabes unis. À l'aide d'un modèle d'étude transversale, des données ont été collectées sur la prévalence de l'automédication auprès d'un échantillon de 6363 adolescents. Au total, 51 \% des participants de cette étude ont rapporté avoir recours à une médication sans ordonnance. La forme la plus courante concernait le paracétamol. Les facteurs prédictifs significatifs de médication sans ordonnance étaient les suivants : la nationalité (Émirats arabes unis, pays du Conseil de Coopération du Golfe/MoyenOrient, arabes/africains, occidentaux et autres) ; un besoin en soins de santé non satisfait ; le sexe (femme) ; l'âge (1518ans); tous types de diagnostic médical ; un usage non conventionnel des médicaments ; le fait de passer plus de cinq heures devant la télévision ou l'ordinateur chaque jour; et de consommer des médicaments délivrés sur ordonnance. Il est donc nécessaire de mettre au point des politiques et des stratégies de santé publique qui fassent la promotion d'un usage approprié des médicaments délivrés sans ordonnance dans la population.

${ }^{1}$ Faculty of Health Sciences, University of Ontario Institute of Technology, Oshawa, Canada. (Correspondence to: C. Barakat-Haddad: Caroline.BarakatHaddad@uoit.ca, ayesha.summer@gmail.com).²Department of Clinical Epidemiology and Biostatistics, McMaster University, Hamilton, Canada.

Received: 30/10/15; accepted: 30/01/17 


\section{Introduction}

In recent years, there has been a rising trend in self-medication with over-the-counter medication (OTC), supported by the absence of regulation for purchase of many drugs without prescription (1). Analgesics are the most frequently purchased OTC (2, 3); the main types being nonsteroidal anti-inflammatory drugs (NSAIDs) and peripheral analgesics.

Benefits of OTC include lower cost than prescription drugs (4), and fewer visits to physicians, leading to lower healthcare costs (5). However, there are also many risks associated with OTC, including physiological adverse effects (e.g., gastrointestinal bleeding and endstage renal disease) or psychological harm (e.g., opiate addiction) (6-8). Other risks include self-misdiagnosis, delay in receiving needed therapy, and increased resistance to antimicrobial agents due to inappropriate use (5). In the United Arab Emirates (UAE), health care and medications are free for all nationals, while healthcare coverage remains optional for expatriates and depends on coverage from private insurance firms (9). The costs of consulting a general practitioner, completing routine and specialist health check-ups, and prescription drugs are high in the $\operatorname{UAE}(10,11)$. The costs in the UAE act as a particular incentive for using OTC, especially for those without medical insurance (9). Harsh judicial penalties for illegal drug use lead to the possibility of OTC abuse by adolescents in the UAE, reflecting the latest trend in drug abuse among this age group in other countries (12,13). In 2012, the 10-19-years age group constituted $8.8 \%$ of the national population in the UAE (14). Screening for risky health behaviours, such as OTC abuse, can facilitate prevention and yield longterm health benefits among adolescents (15). Recent studies have suggested that OTC use is prevalent in the UAE $(16,17)$. Improved knowledge of adolescents' self-medication behaviour in this country is needed to develop public health policies and strategies to preserve their health.

Although use of OTC relates to one's health status or perceptions, it is also affected by geographic and demographic factors $(9,17,18)$. The biopsychosocial model proposes that biological, psychological and social factors interact to determine physical health and illness (19). We used this theoretical model to generate a comprehensive understanding of OTC usage patterns and to examine linkages between multiple dimensions (Figure 1). Notably, while some variables are placed in 1 category, they can be implicitly linked to other categories. For example, "needed healthcare and did not receive it" is classified as a social factor, but it can also be a behavioural factor. The objectives of this study were: (1) to determine the profile of OTC use among UAE adolescents; and (2) to determine the biological or physical, psychological or behavioural, and social predictors of OTC use among the UAE adolescent population.

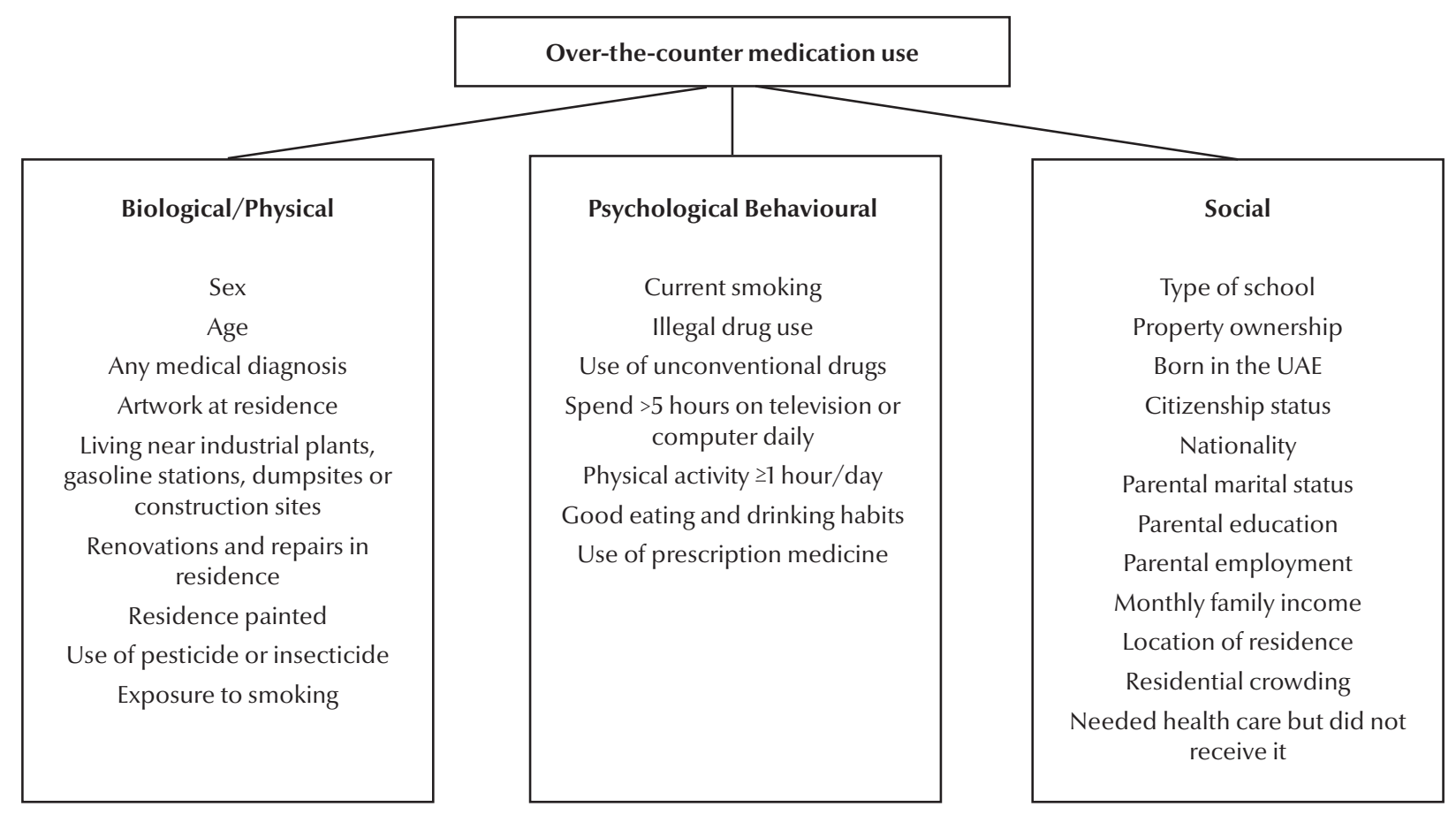

Figure 1 Biopsychological model for assessing predictors of over-the-counter medication use in adolescents in the United Arab Emirates 


\section{Methods}

\section{Data source and design}

This study utilized data from the National Study of Population Health in the UAE (NSPHUAE) that was undertaken in collaboration with the UAE Ministry of Education. A crosssectional survey was administered in 2007-2009 to 6363 adolescents aged 13-20 years, who attended public and private schools throughout the UAE. The first component collected data on smoking behaviour, type and frequency of tobacco use, other determinants of health, self-reported medical diagnoses, healthcare access, as well as demographics and socioeconomics. The second component of the survey collected data on residential location and characteristics [see Barakat-Haddad for more information (20)].

\section{Sampling procedure}

A stratified sampling strategy based on school enrolment data from the UAE Ministry of Education identified the need to select 147 private and public schools from 10 educational zones. Schools were selected randomly by lottery using a 2005-2006 list of schools from the UAE Ministry of Education. For schools that had $>1$ class per grade level, the fishbowl lottery method was used to select 1 class each from grades $10-12$.

\section{Ethics and administration}

Ethical approval was obtained from the UAE Ministries of Education and Health. Social workers were trained to administer the first component of the survey to participants from 3 classes from each selected school during a spare period in a classroom setting. The second component was sent home with the participants overnight to seek parental assistance with completion.

\section{Outcome variable}

The outcome variable was based on the responses to 1 item from the questionnaire. Participants were asked "Do you take any over-the-counter medication on a regular basis (such as Panadol, Tylenol, Advil etc...)?" For this item, participants were provided with 3 responses (yes/no/do not know). If their response was yes, they were asked to specify the medication used. This was an open-ended response option for which participants provided names of all OTC they used on a regular basis.

\section{Explanatory variables}

In meeting the 2 nd objective of this study, explanatory variables included data related to biological or physical, psychological or behavioural, and social variables. Participants' biological or physical profiles included data on sex, age and medical diagnoses. A binary variable, "any medical diagnosis', was created based on whether the participants indicated if they were diagnosed with $\geq 1$ of the following conditions: chronic bronchitis, emphysema, chest disease, skin disease, arthritis, respiratory disorder, high blood pressure, heart disease, thalassaemia, sickle cell anaemia, any type of anaemia, diabetes, kidney disease, ulcer, cancer, migraine, and thyroid disease. To account for physical exposure, participants were asked whether anyone in their household did arts, crafts, ceramics, stained glass work or similar hobbies on a regular basis; whether they lived near industrial plants, gasoline stations, dump sites or construction sites; whether there had been renovations and repairs in their residence in the last 12 months; whether their residence was painted in the last 12 months; whether pesticides or insecticides had ever been used in their home or garden or on their pets; and whether they were exposed to tobacco smoke at home or with friends.

Items concerning psychological or behavioural profiles related to whether the participants had smoked cigarettes, shisha, midwakh or other tobacco products occasionally or daily in the past 30 days. Participants were categorized as current smokers if they reported occasional or daily use of $\geq 1$ form of tobacco in the past 30 days.

In relation to substance abuse, participants were asked if they ever used illegal drugs such as marijuana, hashish or cocaine. In relation to unconventional drug use, participants were asked if they ever purposely inhaled gasoline fumes, glue, correction fluid, car exhaust, or burning black ants. Participants were asked whether they used any of 6 forms of electronic or mobile technology, and about their daily television viewing and computer use (screen time). Participants were asked whether they participated in any of 17 activities in the past 12 months and the number of hours, days and weeks that they participated. A physical activity variable calculated the average number of hours/week of physical activity; this was divided by 7 to determine the average number of hours/day. A threshold $>1$ hour/day of physical activity was considered physically active (21). Participants were also asked if they had good eating and drinking habits, and if they used prescription medicine to maintain their health.

Data related to social profiles included type of school attended; whether the families owned or rented their primary residence; whether the participants were born in the UAE; citizenship status and nationality; parental marital status, education level and employment; and monthly family income. Nationality was classified on the basis of similar cultures, traditions, ancestral links or geographical origins. Parents' employment was categorized as: government employee, private employee, self-employed, and not employed.

We recorded the residential location of the participants: Abu Dhabi, Ajman, Dubai, Fujairah, Ras al-Khaimah, Sharjah or Umm al-Quwain. A residential crowding variable was calculated using the ratio of the number of individuals who resided in the household over the number of bedrooms in the residence. 
Residential crowding was deemed as positive if the ratio was $>2$ or if $>10$ individuals resided in the same household and the number of bedrooms was not reported. Residential crowding was negative if the ratio was $\leq 2$ or if the participants reported $>5$ bedrooms in the household and the number of participants who resided in the household was not reported.

Participants were asked whether they required healthcare in the last 12 months but did not receive it.

\section{Data analysis}

Data were analysed using SPSS version 20. We grouped the OTC reported by participants into the following categories: NSAIDs, peripheral analgesics, NSAIDs and peripheral analgesics, others, mix, and did not specify. The following OTC was grouped as NSAIDs: Advil (ibuprofen), Brufen (ibuprofen), aspirin, Motrin (ibuprofen) and Toradol (ketorolac). The following OTC was grouped as peripheral analgesics: Panadol (paracetamol), Adol (paracetamol), Tylenol (paracetamol), and paracetamol. The NSAIDs and peripheral analgesics category included 1 OTC from each of the above drug groups. The following OTC was grouped as others: Actifed (pseudoephedrine and triprolidine), salicylic acid, acne creams, herbal products, Arabic medications, antibiotics, danazol, Depacon (sodium valproate), Clarinase (loratadine and pseudoephedrine), Trifed (triprolidine) and Tidilor (loratadine). The mix category included NSAIDs, peripheral analgesics and OTC grouped as others. OTC that was described without names was grouped as "did not specify", and included generic OTC descriptions such as painkiller and headache medication. Vitamins were excluded from our categorization of OTC.

Descriptive statistics were calculated for outcome and explanatory variables. $\mathrm{A} \square^{2}$ test was used to compare participants who reported OTC use to those who did not. All independent variables that were significant in the simple univariate analyses were entered into a logistic regression model to predict the probability of OTC use. Conditional forward entry of independent variables was conducted using a significance level of $P \leq 0.05$. Although the physical activity variable was significant in the simple univariate analysis, it was not entered in the regression model due to a large percentage of missing data $(n>4000)$, which limited analysis to 1084 participants, hence the decision was made to remove this variable from the multiple logistic regression.

\section{Results}

Fifty percent of participants were of local national origin and $45 \%$ were male. The mean age of the study sample was 16 years (standard deviation 1.22). Detailed information in relation to the number of schools sampled and response rates has been published elsewhere (20).

Overall, $51 \%$ of participants in this study reported OTC use (Figure 2). The most common form of OTC used was peripheral analgesics (74\%). Overall, $3 \%$ of participants used NSAIDs and $7 \%$ used both NSAIDs and peripheral analgesics.

Significant differences in OTC use were found in relation to all socioeconomic and demographic variables except for family income and residential crowding (Table 1).

Significant differences in OTC use were also found in relation to biologi$\mathrm{cal} /$ physical variables, including: sex; age; any medical diagnosis; whether there were recent renovations and repairs in the residence; whether the residence was recently painted; and whether pesticides or insecticides were used in the home or garden, or on pets (Table 2). For psychological/behavioural variables, significant differences in the prevalence of OTC use were found in relation to unconventional drug use, screen time, physical activity, good eating and drinking habits, and use of prescription medicine (Table 2).

Multiple logistic regression revealed that the following were significant predictors of OTC use: nationality [UAE, Gulf Council Cooperation (GCC), Arab/Middle East, Arab/Africa, Western and other]; needed health care but did not receive it; female sex; age 15-18 years; any medical diagnosis; unconventional drug use; spending $>5$ hours/ day screen time; and using prescription medication (Table 3). Participants with these characteristics had increased odds of using OTC compared to those with the reference characteristics for each of the relevant variables.

\section{Discussion}

Our results suggest a high prevalence of OTC use among the adolescent population in the UAE, with peripheral analgesics as the most commonly used drugs. It has been suggested that physicians have an integral role in identifying and monitoring OTC use and preventing potential drug abuse $(22,23)$. Physicians should be encouraged to screen OTC use and educate adolescents and their families about the proper use of OTC and health risks of self-medication (22). Since pain relievers are the most frequently purchased OTC drugs, it would be beneficial for physicians to treat pain appropriately (24). Education campaigns and activities that focus on increasing parents' knowledge about OTC are particularly important given that children who learn about the risks of OTC from their parents are less likely to use them (12). Pharmacists should be encouraged to question adolescents regarding frequent refills of the most commonly abused medications (12).

Our results show that adolescents from the UAE, GCC, Arab/Middle East, Arab/Africa, and western regions are more likely to use OTC compared to South-East Asians. Given that UAE 


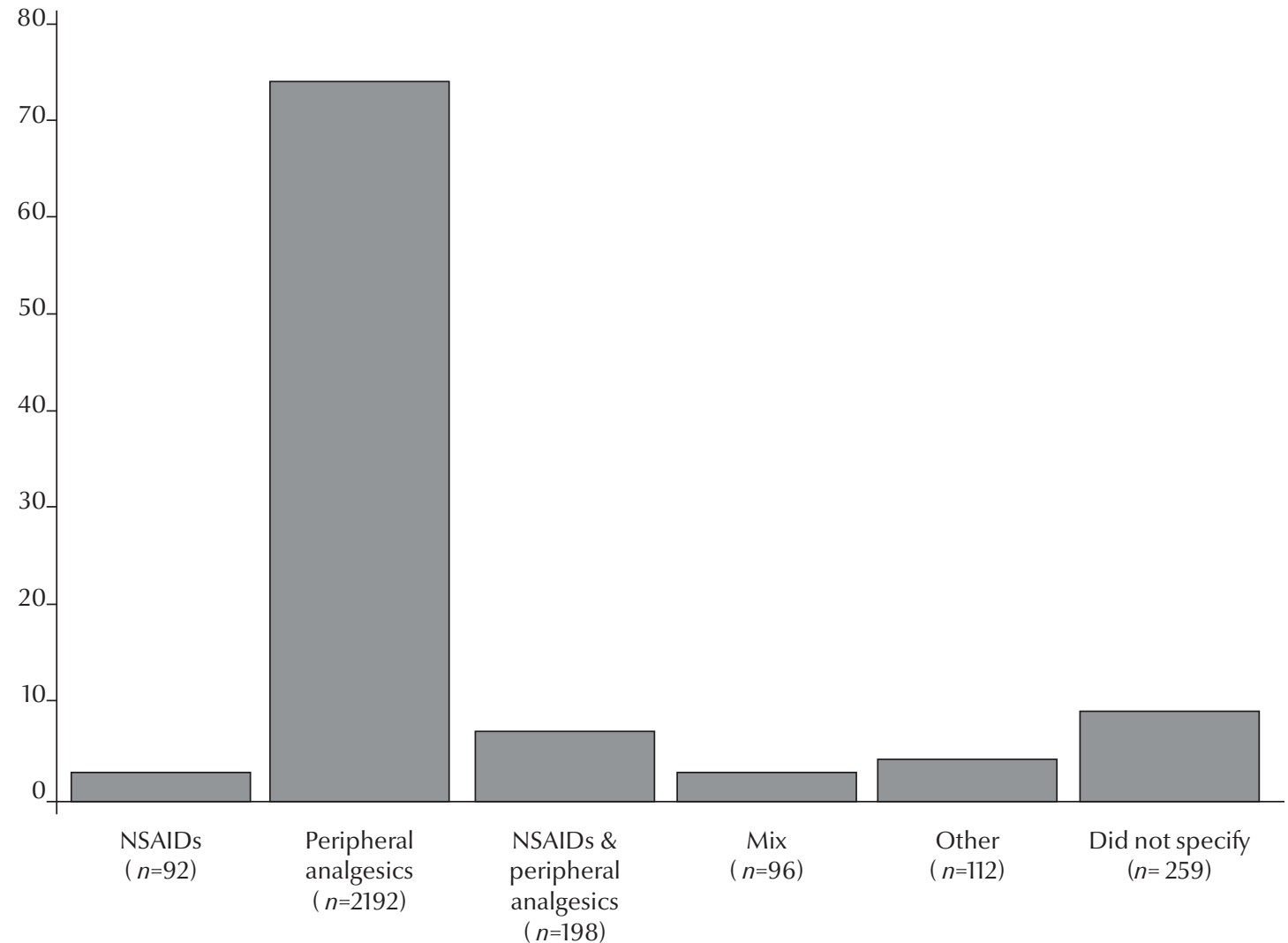

Figure 2 Number and percentage of over-the-counter drug use among adolescents residing in the United Arab Emirates ( $n=$ 2935). NSAIDs = nonsteroidal anti-inflammatory drugs

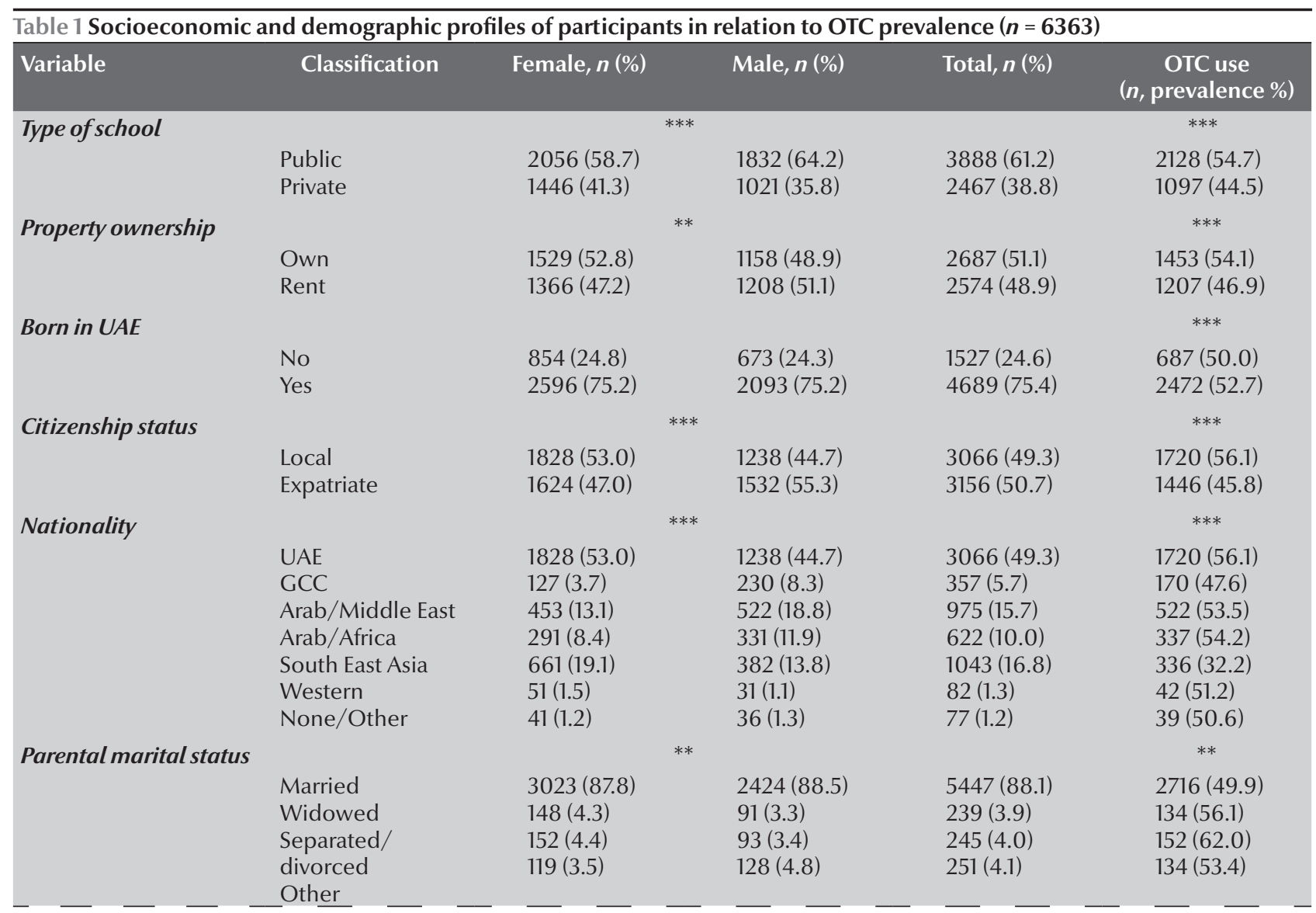




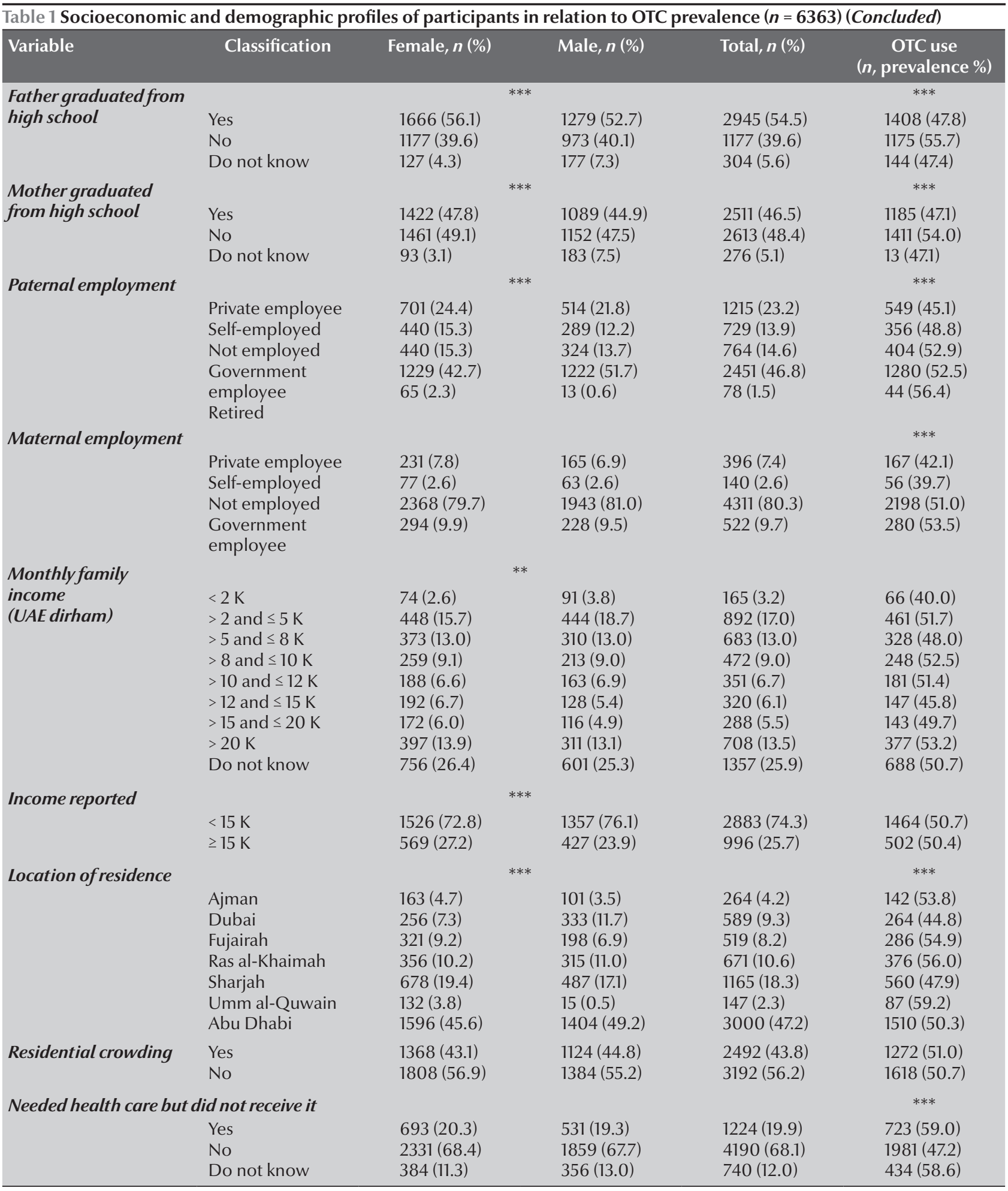

${ }^{*} P<0.05 ;{ }^{* *} P<0.01 ;{ }^{* * *} P<0.001$.

nationals receive free health care and medication, our findings suggest that factors other than cost may influence the choice of self-medication. SouthEast Asian expatriates, many of whom are blue-collar workers and usually do not have health coverage (10), are less likely to use OTC than expatriates from other regions. This finding contradicts the hypothesis that lack of health coverage is related to self-medication using OTC.

Our results show that adolescents who do not receive needed health care are more likely to use OTC. This highlights the possible socioeconomic disadvantage in maintaining health adolescents who are unable to access health care due to cost also opt for cheaper self-medication. It is encouraging to note that after the completion 


\begin{tabular}{|c|c|c|c|c|c|}
\hline Variable & classification & Female, n (\%) & Male, $\mathbf{n}(\%)$ & Total, n (\%) & $\begin{array}{c}\text { OTC use, } \mathbf{n} \\
\text { (prevalence \%) }\end{array}$ \\
\hline \multirow[t]{3}{*}{ Sex } & & & & & $* * *$ \\
\hline & Female & & & $3458(55.3)$ & $1907(55.1)$ \\
\hline & Male & & & $2791(44.7)$ & $1318(47.2)$ \\
\hline \multirow{7}{*}{ Age, yr } & \multicolumn{3}{|c|}{$* * *$} & & $*$ \\
\hline & $<14$ & $208(6.0)$ & $119(4.2)$ & 1327 (5.2) & $152(11.5)$ \\
\hline & 15 & $1025(29.4)$ & $777(27.4)$ & $1802(28.5)$ & $897(49.8)$ \\
\hline & 16 & $1077(30.9)$ & $772(27.2)$ & $1849(29.2)$ & $941(50.1)$ \\
\hline & 17 & $874(25.0)$ & $808(28.5)$ & $1682(26.6)$ & $907(54.0)$ \\
\hline & 18 & $211(6.0)$ & $226(8.0)$ & $437(6.9)$ & $211(48.3)$ \\
\hline & $>19$ & $96(2.7)$ & $132(4.7)$ & $228(3.6)$ & $102(44.7)$ \\
\hline \multirow[t]{3}{*}{ Any medical diagnosis } & \multicolumn{4}{|c|}{$* * *$} & *** \\
\hline & Yes & $1472(42.0)$ & $986(34.6)$ & $2458(38.7)$ & $1461(59.4)$ \\
\hline & No & $2030(58.0)$ & $1867(65.4)$ & $3897(61.3)$ & $1764(45.3)$ \\
\hline \multirow{2}{*}{$\begin{array}{l}\text { Arts, crafts, ceramics or stained } \\
\text { glass work at residence }\end{array}$} & Yes & $578(19.2)$ & $423(17.4)$ & $1001(18.4)$ & $502(50.2)$ \\
\hline & No & $2425(80.8)$ & $2011(82.6)$ & 4436 (81.6) & $2245(50.6)$ \\
\hline \multirow{3}{*}{$\begin{array}{l}\text { Live near industrial plants, } \\
\text { gasoline stations, dumpsites or } \\
\text { construction sites }\end{array}$} & \multicolumn{4}{|c|}{ * } & \\
\hline & Yes & $425(14.3)$ & $392(16.2)$ & $817(15.1)$ & $412(50.4)$ \\
\hline & No & $2555(85.7)$ & $2021(83.8)$ & $4576(84.9)$ & $2309(50.4)$ \\
\hline \multirow[t]{3}{*}{ Renovations and repairs in residence } & \multicolumn{4}{|c|}{$* * *$} & $* * *$ \\
\hline & Yes & 1948 (64.9) & $1477(60.3)$ & $3425(62.9)$ & $1796(52.4)$ \\
\hline & No & $1052(35.1)$ & $972(39.7)$ & $2024(37.1)$ & $951(47.0)$ \\
\hline \multirow{2}{*}{ Residence painted } & Yes & $1680(561)$ & $1245(508)$ & $2925(537)$ & $1522(520)$ \\
\hline & No & $1317(43.9)$ & $1206(49.2)$ & $2523(46.3)$ & $1224(48.5)$ \\
\hline \multirow{4}{*}{ Use of pesticide or insecticide } & & & & & \\
\hline & Yes & $2084(70.1)$ & $1595(65.9)$ & $3679(68.2)$ & $1913(52.0)$ \\
\hline & No & $753(25.3)$ & $664(27.4)$ & $1417(26.3)$ & $636(44.9)$ \\
\hline & $\begin{array}{l}\text { Do not } \\
\text { know }\end{array}$ & $138(4.6)$ & $162(6.7)$ & $300(5.6)$ & $163(54.3)$ \\
\hline \multirow[t]{3}{*}{ Exposure to smoking } & \multicolumn{4}{|c|}{$* * *$} & \\
\hline & Yes & $915(31.1)$ & $1234(49.5)$ & 2149 (39.5) & 1119 (52.1) \\
\hline & No & $2030(68.9)$ & $1257(50.5)$ & $3287(60.5)$ & $1636(49.8)$ \\
\hline \multirow[t]{3}{*}{ Current smoking } & \multicolumn{4}{|c|}{$* * *$} & \\
\hline & Yes & $175(5.5)$ & $643(24.2)$ & $818(14.0)$ & $423(51.7)$ \\
\hline & No & $2991(94.5)$ & $2015(75.8)$ & $5006(86.0)$ & $2534(50.6)$ \\
\hline \multirow[t]{3}{*}{ Illegal drug use } & \multicolumn{4}{|c|}{$* * *$} & \\
\hline & Yes & $19(0.6)$ & 76 (2.7) & $95(1.6)$ & 48 (50.5) \\
\hline & No & $3231(99.4)$ & $2695(97.3)$ & $5926(98.4)$ & $2993(50.5)$ \\
\hline \multirow{6}{*}{$\begin{array}{l}\text { Use of unconventional drugs } \\
\text { (purposely inhaling gas, glue, } \\
\text { correction fluid or burnt black } \\
\text { ants) } \\
\text { Spent }>5 \mathrm{~h} / \mathrm{d} \text { on screen }\end{array}$} & \multicolumn{4}{|c|}{$* * *$} & $* *$ \\
\hline & Yes & $1210(37.3)$ & $550(20.0)$ & $1760(29.4)$ & $948(53.9)$ \\
\hline & No & $2031(62.7)$ & $2031(80.0)$ & $4232(70.6)$ & $2079(49.1)$ \\
\hline & & & & & $* * *$ \\
\hline & Yes & $1297(38.4)$ & $1012(37.4)$ & $2309(38.0)$ & $1288(55.8)$ \\
\hline & No & $2082(61.6)$ & $1693(62.6)$ & $3775(62.0)$ & $1817(48.1)$ \\
\hline Physical activity $\geq 1 \mathrm{~h} / \mathrm{d}$ & & & & & $*$ \\
\hline & Yes & $166(14.6)$ & $341(28.4)$ & $507(21.6)$ & $239(47.1)$ \\
\hline & No & $974(85.4)$ & $861(71.6)$ & $1835(78.4)$ & $963(52.5)$ \\
\hline Good eating and drinking habits & & & & & $* * *$ \\
\hline & Yes & 1215 (35.3) & 1110 (40.5) & $2325(37.6)$ & $1112(47.8)$ \\
\hline & No & $2230(64.7)$ & $1632(59.5)$ & $3862(62.4)$ & $2044(52.9)$ \\
\hline Use of prescription medicine & & & & & $* * *$ \\
\hline & Yes & 575 (21.9) & 311 (14.3) & 886 (18.5) & $526(59.4)$ \\
\hline & No & $2045(78.1)$ & $1870(85.7)$ & $3915(81.5)$ & $1773(45.3)$ \\
\hline
\end{tabular}

${ }^{*} P<0.05 ;{ }^{* *} P<0.01 ;{ }^{* * *} P<0.001$.

of our study, manufacturers agreed to lower the price of drugs sold to local agents; possibly affecting $94 \%$ of the products registered in the UAE (25).
Consistent with the literature, our results suggest that women are more likely to use OTC than men are (23, 26-29). It has been suggested that women may be more likely to use painkillers due to menstrual pain $(29,30)$. It is also possible that women generalize their knowledge of the efficacy of OTC 


\begin{tabular}{|c|c|c|c|}
\hline \multirow[t]{2}{*}{ Variable } & \multirow[t]{2}{*}{ Reference } & \multicolumn{2}{|c|}{ OTC use } \\
\hline & & OR & $95 \% \mathrm{Cl}$ \\
\hline \multicolumn{4}{|l|}{ Nationality } \\
\hline South-East Asia & & - & - \\
\hline UAE & & 2.87 & $2.30-3.58$ \\
\hline GCC & & 1.85 & $1.28-2.68$ \\
\hline Arab/Middle East & & 2.91 & $2.24-3.79$ \\
\hline Arab/Africa & & 3.41 & $2.53-4.58$ \\
\hline Western & & 2.79 & $1.46-5.33$ \\
\hline Other & & 1.60 & $0.83-3.08$ \\
\hline \multicolumn{4}{|c|}{ Needed health care but did not receive it } \\
\hline \multicolumn{4}{|c|}{ No } \\
\hline Yes & & 1.34 & $1.09-1.65$ \\
\hline Do not know & & 1.60 & $1.25-2.05$ \\
\hline \multicolumn{4}{|l|}{ Sex } \\
\hline Male & & 1.39 & $1.19-1.63$ \\
\hline Female & & - & - \\
\hline \multicolumn{4}{|l|}{ Age, yr } \\
\hline$\geq 19$ & & 0.96 & $0.56-1.67$ \\
\hline$\leq 14$ & & 1.09 & $0.69-1.74$ \\
\hline 15 & & 1.03 & $0.65-1.63$ \\
\hline 16 & & 1.40 & $0.88-2.22$ \\
\hline 17 & & 1.16 & 0.68-1.95 \\
\hline 18 & & 1.38 & $1.15-1.64$ \\
\hline \multicolumn{4}{|l|}{ Any medical diagnosis } \\
\hline Yes & & - & - \\
\hline No & & - & - \\
\hline \multicolumn{4}{|c|}{$\begin{array}{l}\text { Use of unconventional drugs (purposely inhaling gas, glue, } \\
\text { correction fluid or burnt black ants) }\end{array}$} \\
\hline Yes & & 1.32 & $1.11-1.56$ \\
\hline No & & - & - \\
\hline \multicolumn{4}{|l|}{ Spent $>5 \mathrm{~h} / \mathrm{d}$ on screen } \\
\hline$<5 \mathrm{~h}$ & & 1.25 & $1.06-1.46$ \\
\hline$\geq 5 \mathrm{~h}$ & & - & - \\
\hline \multicolumn{4}{|l|}{ Use of prescription medicine } \\
\hline Yes & & 1.67 & $1.38-2.01$ \\
\hline No & & - & - \\
\hline Hosmer and Lemeshow test $\left(\square^{2}\right)$ & & \multicolumn{2}{|c|}{12.016} \\
\hline
\end{tabular}

for menstrual pain to other types of pain that they may experience (30). In our study, we did not have access to information regarding the indications or symptoms for which adolescents use OTC drugs. Future research should examine the indications and symptoms related to OTC use, facilitating further exploration of the observed sex difference in self-medication.

Our results indicate that adolescents aged 15-18 years are more likely to use OTC than those aged $\geq 19$ years. Evidence shows that rates of substance use and illegal drug use typically increase during adolescence, as freedom and independence experienced during this period of life increase, but as young adults commit to new roles and responsibilities, a general decline in substance use is observed (31). Our findings also show that adolescents with any medical diagnoses are more likely to use OTC. It is possible that adolescents may also choose to or need to self-medicate when they have a medical diagnosis. 
Results suggest that adolescents who use unconventional drugs, such as purposely inhaling gas, glue, correction fluid or burnt black ants, are more likely to use OTC than adolescents who do not use these drugs. It may be that adolescents who use unconventional drugs are also prone to the use of certain OTC, as a result of generalizing to OTC their expectation of getting high through unconventional drugs. Additionally, we found that adolescents who spend > 5 hours/day on screen are more likely to use OTC than adolescents who do not. This is not surprising, as there is a positive association between time spent on sedentary screen-based activities and backache and headache $(32,33)$. Adolescents who have a lot of daily screen time may need to purchase OTC medication to relieve any associated pain. Furthermore, our findings show that adolescents who use prescription medicine to maintain their health are also more likely to use OTC. This raises concerns regarding clinically significant drug interactions. Through clinical practice guidelines, physicians should be encouraged to inform patients regarding the possibility of drug reactions when prescribing medication.

Although most of the explanatory variables were significantly associated with OTC use in the univariate analyses, many of these variables were not significant predictors of OTC use in multiple logistic regression. This was true for type of school attended; family property ownership; birth in the UAE and citizenship status; parental marital status, education level and employment; location of residence and renovations, repairs and painting in residence; use of pesticides or insecticides; physical activity; and eating and drinking habits. Nevertheless, the previously mentioned variables are important to consider when developing public health strategies, as they were all significantly associated with OTC use in the univariate analyses. Furthermore, some of these variables have been identified in recent literature, as factors associated with OTC use. For example, adults with little physical activity had 1.5-4 times greater risk of daily OTC analgesic use compared to physically active individuals (34).

Our study had several limitations. Currently, there are no international or region-specific definitions for OTC. In our study, participants were not provided with a definition of OTC and were only asked if they took any OTC on a regular basis. This may limit the comparison of our results with those of other studies in which OTC may have been conceptualized differently. Data were self-reported and may have been subject to response bias. We did not have access to information regarding the strength, composition, form, presentation and frequency of OTC use per person for a specific duration of time. We also did not have information regarding the reasons for OTC use. Sampling led to lower representations of adolescents who attended private schools in Dubai and among men who resided in Umm al-Quwain. This is relevant as the population of Dubai consists of a large proportion of expatriates; hence, results related to the expatriate population in Dubai are likely to be biased.

Despite the above limitations, this study contributes to our understanding of the profile and predictors of OTC use among UAE adolescents, which is crucial for setting policy priorities to serve this population better. Future research should explore the scale of potential OTC abuse in this population, to implement and evaluate interventions to inform policy, regulation and interventions.

\section{Funding: None.}

Competing interests: None declared.

\section{References}

1. Leeies M, Pagura J, Sareen J, Bolton JM. The use of alcohol and drugs to self-medicate symptoms of posttraumatic stress disorder. Depress Anxiety. 2010 Aug;27(8):731-6. PMID:20186981

2. Kaufman DW, Kelly JP, Rosenberg L, Anderson TE, Mitchell AA. Recent patterns of medication use in the ambulatory adult population of the United States: the Slone survey. JAMA. 2002 Jan 16;287(3):337-44. PMID:11790213

3. Abbott FV, Fraser MI. Use and abuse of over-the-counter analgesic agents. J Psychiatry Neurosci. 1998 Jan;23(1):13-34. PMID:9505057

4. Hughes CM, McElnay JC, Fleming GF. Benefits and risks of self medication. Drug Saf. 2001;24(14):1027-37. PMID:11735659

5. Brass EP. Changing the status of drugs from prescription to over-the-counter availability. N Engl J Med. 2001 Sep 13;345(11):810-6. PMID:11556302

6. Curhan GC, Bullock AJ, Hankinson SE, Willett WC, Speizer FE, Stampfer MJ. Frequency of use of acetaminophen, nonsteroidal anti-inflammatory drugs, and aspirin in US women. Pharmacoepidemiol Drug Saf. 2002 Dec;11(8):687-93. PMID:12512245
7. Singh G. Gastrointestinal complications of prescription and over-the-counter nonsteroidal anti-inflammatory drugs: a view from the ARAMIS database. Arthritis, Rheumatism, and Aging Medical Information System. Am J Ther. 2000 Mar;7(2):115-21. PMID:11319579

8. Thomas J, Straus WL, Bloom BS. Over-the-counter nonsteroidal anti-inflammatory drugs and risk of gastrointestinal symptoms. Am J Gastroenterol. 2002 Sep;97(9):2215-9. PMID:12358235

9. Zaghloul AA, Elsergany M, El-Enein NA, Alsuwaidi H, Ayoub M. Over-the-counter medication patterns in households in Sharjah, United Arab Emirates. Risk Manag Healthc Policy. 2013;7:19-24. PMCID:PMC3883161

10. Maceda C. Health care cost most expensive in UAE (http:// www.zawya.com/story/Health_care_cost_most_expensive_ in_UAE-GN_21012014_220140/, accessed 29 May 2017).

11. Sophia M. UAE Slashes Prices of 205 Drugs (http://gulfbusiness.com/uae-slashes-prices-of-205-drugs/, accessed 29 May 2017). 
12. Levine DA. "Pharming": the abuse of prescription and over-thecounter drugs in teens. Curr Opin Pediatr. 2007 Jun;19(3):2704. PMID:17505185

13. Overseas Security Advisory Council. United Arab Emirates 2013 crime and safety report: Abu Dhabi (https://www.osac.gov/ Pages/ContentReportDetails.aspx? cid=13886, accessed 29 May 2017)

14. United Nations Children's Fund. United Arab Emirates. Statistics. 2013 (https://www.unicef.org/infobycountry/uae_statistics.html, accessed 29 May 2017).

15. Ham P, Allen C. Adolescent health screening and counseling Am Fam Physician. 2012 Dec 15;86(12):1109-16 (http://www. aafp.org/afp/2012/1215/p1109.html).

16. Abasaeed A, Vlcek J, Abuelkhair M, Kubena A. Self-medication with antibiotics by the community of Abu Dhabi Emirate, United Arab Emirates. J Infect Dev Ctries. 2009 Aug 30;3(7):491-7. PMID:19762966

17. Shehnaz SI, Khan N, Sreedharan J, Issa KJ, Arifulla M. Selfmedication and related health complaints among expatriate high school students in the United Arab Emirates. Pharm Pract (Granada). 2013 Oct;11(4):211-8. PMID:24367461

18. Porteous T, Bond C, Hannaford P, Sinclair H. How and why are non-prescription analgesics used in Scotland? Fam Pract. 2005 Feb;22(1):78-85. PMID:15640291

19. Suls J, Rothman A. Evolution of the biopsychosocial model: prospects and challenges for health psychology. Health Psychol. 2004 Mar;23(2):119-25. PMID:15008654

20. Barakat-Haddad C. Prevalence of high blood pressure, heart disease, thalassemia, sickle-cell anemia, and iron-deficiency anemia among the UAE adolescent population. J Environ Public Health. 2013;2013:680631. PMID:23606864

21. Centres for Disease Control and Prevention. How much physical activity do children need? (http://www.cdc.gov/physicalactivity/everyone/guidelines/children.html/, accessed 29 May 2017).

22. Shi CW, Bayard MA. Abuse of over-the-counter medications among teenagers and young adults. Am Fam Physician. 2011 Oct 1;84(7):745-50. PMID:22010610

23. Sihvo S, Klaukka T, Martikainen J, Hemminki E. Frequency of daily over-the-counter drug use and potential clinically significant over-the-counter-prescription drug interactions in the Finnish adult population. Eur J Clin Pharmacol. 2000 Sep;56(6-7):495-9. PMID:11049013
24. Lessenger JE, Feinberg SD. Abuse of prescription and overthe-counter medications. J Am Board Fam Med. 2008 JanFeb;21(1):45-54. PMID:18178702

25. Abahussain E, Matowe LK, Nicholls PJ. Self-reported medication use among adolescents in Kuwait. Med Princ Pract. 2005 May-Jun;14(3):161-4. PMID:15863989

26. Dengler R, Roberts H. Adolescents' use of prescribed drugs and over-the-counter preparations. J Public Health Med. 1996 Dec;18(4):437-42. PMID:9023803

27. Hansen EH, Holstein BE, Due P, Currie CE. International survey of self-reported medicine use among adolescents. Ann Pharmacother. 2003 Mar;37(3):361-6. PMID:12639163

28. Sleath B, Rubin RH, Campbell W, Gwyther L, Clark T. Physicianpatient communication about over-the-counter medications. Soc Sci Med. 2001 Aug;53(3):357-69. PMID:11439819

29. Wilcox CM, Cryer B, Triadafilopoulos G. Patterns of use and public perception of over-the-counter pain relievers: focus on nonsteroidal antiinflammatory drugs. J Rheumatol. 2005 Nov;32(11):2218-24. PMID:16265706

30. Chambers CT, Reid GJ, McGrath PJ, Finley GA. Self-administration of over-the-counter medication for pain among adolescents. Arch Pediatr Adolesc Med. 1997 May;151(5):449-55. PMID:9158435

31. Botvin GJ, Griffin KW. School-based programmes to prevent alcohol, tobacco and other drug use. Int Rev Psychiatry. 2007 Dec;19(6):607-15. PMID:18092239

32. Torsheim T, Eriksson L, Schnohr CW, Hansen F, Bjarnason T, Valimaa R. Screen-based activities and physical complaints among adolescents from the Nordic countries. BMC Public Health. 2010 Jun 9;10:324. PMID:20534116

33. Hakala PT, Rimpela AH, Saarni LA, Salminen JJ. Frequent computer-related activities increase the risk of neck-shoulder and low back pain in adolescents. Eur J Public Health. 2006 Oct;16(5):536-41. PMID:16524936

34. Dale O, Borchgrevink PC, Fredheim OM, Mahic M, Romundstad P, Skurtveit S. Prevalence of use of non-prescription analgesics in the Norwegian HUNT3 population: impact of gender, age, exercise and prescription of opioids. BMC Public Health. 2015 May 2;15:461. PMID:25934132 